\title{
PENGEMBANGAN AGRIBISNIS DAN NILAI TAMBAH KOPI MELALUI SKALA RUMAH TANGGA PETANI
}

\author{
Albina Ginting ${ }^{1}$ Sarma Bakkara ${ }^{2}$ \\ Fakultas Pertanian Universitas HKBP Nommensen, Medan ${ }^{1}$ \\ Fakultas Pertanian Universitas HKBP Nommensen, Medan² \\ Alamat email: albinamunthe@gmail.com
}

\begin{abstract}
Abstrak
Produk pertanian yang menjadi unggulan di Desa Pardomuan Motung Kecamatan Ajibata adalah kopi. Permasalahan yang dihadapi oleh petani kopi di daerah ini adalah menurunnya produksi kopi selama beberapa tahun terakhir serta minimnya pengetahuan petani tentang pengolahan dan peningkatan mutu kopi. Tujuan kegiatanj ini adalah untuk meningkatkan pengetahuan dan ketrampilan kelompok tanidi bidang usaha tani kopi dan pengolahan kopi sebagai produk unggulan daerah. Selanjutnya meningkatkan kualitas dan mutu kopi serta daya tarik produk sehingga memiliki daya saing tinggi. Memperkuat kelompok usaha masyarakat sehingga dapat memberikan pendapatan bagi masyarakat sekitar.
\end{abstract}

Kata Kunci: Pendapatan, Daya Saing, Mutu, Produksi

\begin{abstract}
The agricultural product that had emerged in the village of pardomuan motung the ajibata district was the coffee. Among the problems that coffee farmers have faced in this area are the decline in coffee production over the past few years and that farmers have a knowledge of the processing and improvement of coffee. The goal of this activity is to improve the knowledge and skills of the group of tanal-coffee and coffee processing as previews of the region. In turn, it enhances the quality and quality of the coffee and the appeal of the product to a high competitiveness. Strengthen community business groups so as to provide income for the people around them.
\end{abstract}

Keywords: Income, Competitiveness, Quality, Production

\section{PENDAHULUAN}

Sumatera utara merupakan salah satu provinsi yang daerahnya berpotensi untuk pengembangan budidaya kopi. Beberapa daerah atau kabupaten yang terkenal dengan produksi kopinya adalah Kabupaten Dairi, Kabupaten Tapanuli Utara, Kabupaten Tobasa, dan Humbahas dan kabupaten lainnya yang potensial untuk pertanaman komoditi perkebunan ini. Adapun jenis kopi yang dibudidayakan di Sumatera utara ini adalah kopi jenis arabika dan robusta. Sebagai salah satu provinsi penghasil kopi terbesar di Indonesia, produksi kopi mampu menunjang pendapatan asli daerah bagi daerah-daerah pertanaman kopi sekaligus meningkatkan pemasukan bagi pendapatan Propinsi Sumatera Utara terutama dari hasil ekspor ke luar negeri.

Desa Pardomuan Motung merupakan salah satu desa yang berada di Kecamatan Ajibata Kabupaten Toba Samosir yang terletak pada ketinggian 1.300 mdpl dengan letak geografis berada ada 2,6035 LU (latitude) dan 99.11786 BT 
(longitude). Desa ini memiliki luas wilayah $6 \mathrm{~km}^{2}$ dan rasio terhadap luas kecamatan sebesar $8,24 \%$ dengan jumlah penduduk 379 jiwa yang terdiri atas laki-laki sebanyak 193 jiwa dan perempuan 186 jiwa, dengan tingkat kepadatan penduduk 63,17 jiwa/ km². Desa Pardomuan Motung (BPS, Kecamatan Ajibata Dalam Angka, 2017).

Desa Pardomuan Motung terdiri atas 3 (tiga) dusun, yaitu Dusun I, II dan Dusun III, dan jarak Desa Pardomuan Motung ke ibu kota kecamatan sekitar $5 \mathrm{~km}$. Luas wilayah Desa Pardomuan Motung menurut jenis penggunaan tanah dan desa/ kelurahan tahun 2016 adalah lahan sawah 17 ha, tanah kering 71 ha, bangunan/ pekarangan 11 ha, dan 125 ha untuk penggunaan lainnya (BPS, Kecamatan Ajibata Dalam Angka, 2017).

Mayoritas penduduk Desa Pardomuan Motung menggantungkan kehidupannya pada sektor pertanian yaitu usahatani tanaman pangan, perkebunan rakyat dan peternakan. Usahatani tanaman pangan yang dikelola masyarakat meliputi usahatani padi sawah dengan luas lahan 17 ha dengan sistem irigasi sederhana/ tadah hujan dengan produksi 90.1 ton dan produktifitas 5,3 ton/ ha dan lahan bukan sawah sekitar 143 ha. Di samping usahatani padi sawah terdapat usahatani pangan lainnya seperti; usahatani jagung dengan luas lahan 121 ha dengan produksi 1.152 ton dan produktifitas 6,8 ton/ha, kemudian usahatani ubi kayu dengan luas 15 ha dengan produksi 212,8 ton dengan produktifitas 5,7 ton/ ha.

Di samping usahatani tanaman pangan, masyarakat Desa Pardomuan Motung mengandalkan perkebunan rakyat yaitu; usahatani tanaman kopi sebagai sumber penghasilan utama. Komoditi kopi yang dikembangkan masyarakat di wilayah ini seluas 60 ha namun rata-rata usahatani kopi yang dikembangkan di wilayah ini sudah berumur 5-10 tahun artinya membutuhkan replanting. Masyarakat yang mengembangkan usahatani kopi di daerah ini juga memiliki kelompok tani. Sampai tahun 2017 jumlah kelompok tani di daerah ini sebanyak 4 kelompok tani namun mayoritas kelompok tani di daerah ini sangat membutuhkan pendampingan agar lebih berkembang. Permasalahan yang dihadapi oleh petani kopi di daerah ini adalah menurunnya produksi kopi selama beberapa tahun terakhir serta mimnya pengetahuan petani tentang pengolahan dan peningkatan mutu kopi.

\section{Identifikasi dan Perumusan Masalah}

Adapun permasalahan yang ditemukan di lapangan adalah: 
1) Produksi usahatani kopi umumnya dijual dalam bentuk gabah kering, dan jika produksi sedikit akan dijual dalam bentuk gabah basah, dengan harga yang sangat rendah.

2) Share margin yang diperoleh anggota kelompok tani masih kecil, karena petani mengeluarkan tambahan biaya untuk proses transportasi menuju pasar pekan.

3) Kelompok tani belum mampu membentuk koperasi, yang dapat berperan sebagai saluran pemasaran yang efektif bagi semua anggota kelompok.

4) Rendahnya kemampuan anggota kelompok tani untuk meningkatkan nilai tambah produk kopi (kopiolahan/bubuk).

\section{Tujuan Pengabdian}

Adapun tujuan dalam pengabdian ini adalah:

1. Untuk memberikan pemahaman bagi petani agar mampu mengembangkan proses pengolahan kopi untuk meningkatkan nilai tambah.

2. Untuk memberikan pemahaman kepada kelompok tani tentang peran koperasi sebagai salah satu cara mengembangkan sistem pemasaran untuk menurunkan biaya transportasi.

\section{TINJAUAN PUSTAKA}

\section{Pengembangan Agribisnis Kopi Berbasis Kerakyatan}

Sebagai bagian dari pembangunan daerah maka secara umum pembangunan sektor pertanian harus diarahkan kepada pendekatan pembangunan berbasis kerakyatan. Berbagai hasil pembangunan terutama yang berkaitan dengan upaya pemberdayaan masyarakat perkebunan, umumnya mempunyai margin pendapatan yang besar, yang lebih banyak dinikmati oleh pengusaha besar, belum banyak dinikmati oleh petani. Karena Petani hanya menikmati pendapatan produksi (on farm) saja (Admaizon, 2004).

Subsektor perkebunan merupakan salah satu bisnis strategis dan andalan dalam perekonomian Indonesia, bahkan pada masa krisis ekonomi. Agribisnis subsektor ini mempunyai kontribusi yang signifikan terhadap stabilitas ekonomi makro, pertumbuhan, penciptaan lapangan kerja, penerimaan devisa dari ekspor, dan sumber bahan baku bagi industri hilir hasil pertanian (Susila dan Drajat, 2009). 
Kopi hingga saat ini masih merupakan salah satu komoditi hasil perkebunan yang penting dalam perekonomian nasional. Kopi yang dimaksud di sini adalah kopi robusta, dari total produksi kopi Indonesia sekitar 90\% adalah kopi robusta dan $10 \%$ kopi arabika. Dari jumlah kopi yang diperdagangkan di pasar internasional 70\% nya adalah kopi robusta, dan 30\% kopi Arabika (Kustari, 2007). Kopi merupakan salah satu komoditas andalan perkebunan yang mempunyai kontribusi cukup nyata dalam perekonomian Indonesia, yaitu sebagai penghasil devisa, sumber pendapatan petani, penghasil bahan baku industri, Penciptaan lapangan kerja dan pengembangan wilayah.

\section{Proses Pengolahan Biji Kopi}

Pada tanaman kopi dikenal dua macam proses, antara lain:

1. Proses kering

Proses kering amat sederhana dan tidak memerlukan peralatan khusus. Setelah dipetik, kopi biasanya dikeringkan dengan cara dijemur selama 10 sampai 15 hari setelah itu kopi tersebut dikupas. Hampir semua kopi Arabika dari Brazil melalui proses kering, dan kualitasnya tetap bagus karena kopi yang dipetik biasanya yang telah betul-betul matang atau berwarna merah.

2. Proses basah

Pada proses basah diperlukan peralatan khusus dan hanya bisa memproses biji kopi yang telah benar-benar matang. Proses jenis ini biasanya dilakukan oleh perkebunan besar dengan peralatan yang memadai termasuk mekanik yang memadai sehingga mereka tidak tergantung pada cahaya matahari untuk mengeringkan kopi tersebut. Beberapa keuntungan dari pengolahan secara basah adalah proses lebih cepat, kapasitas pengolahan lebih besar, dan dihasilkan biji kopi yang mutunya relatif baik. Kelemahan-kelemahan cara tersebut antara lain biaya pengolahan lebih mahal, memerlukan investasi sarana yang cukup mahal dan menyebabkan pencemaran lingkungan karena air buangan pengolahan. Ukuran biji kopi merupakan salah satu elemen penting dari kualitasnya yang berpengaruh pada harga jual kopi tersebut. Beberapa faktor yang mempengaruhi ukuran biji tersebut antara lain varietas tanaman yang ditanam, cuaca, ketinggian daerah tanam, kesuburan tanah, sistem pemotongan saat panen. Biji kopi yang baru dipetik berwarna kehijauan, semakin lama disimpan warnanya semakin gelap. Biji kopi yang baru datang, tidak langsung diolah melainkan dijemur terlebih dahulu selama sekitar tujuh jam. Setelah dijemur, biji kopi 
dimasukkan karung goni yang kemudian akan diperam di gudang kopi. Pemeraman ini dimaksudkan untuk menghilangkan sifat jelek kopi, yaitu mengurangi kadar kafein dan menghilangkan kadar asam kopi sehingga kopi aman untuk diminum. Proses pemeraman ini berlangsung delapan tahun untuk kopi Arabika dan lima tahun untuk kopi Robusta karena kopi robusta kandungan asamnya tidak sebanyak kopi Arabika. Setelah diperam, kopi disangrai selama kurang lebih dua jam dengan menggunakan mesin.

\section{METODE PELAKSANAAN}

Kegiatan ini dilaksanakan di Kantor Desa Motung Kecamatan Ajibata kabupaten Tobasa pada hari Sabtu tanggal 29 Pebruari 2020. Peserta yang diikutsertakan dalam kegiatan ini adalah kelompok tani kopi Desa Motung. Adapun metode pelaksanaan kerja yang dilakukan dalam pengabdian ini adalah dalam bentuk Focus Group Discussion (FGD), dan ceramah/penyuluhan.

\section{HASIL DAN PEMBAHASAN}

\section{Strategi pengembangan dan peningkatan nilai tambah kopi}

Strategi pengembangan agribisnis kopi yang dipaparkan dalam kegiatan ini adalah antara lain : Perbaikan tanaman melalui peremajaan, rehabilitasi, Intensifikasi, Perluasan tanaman, Kelembagaan, Gapoktan, Koperasi, Bibit tanaman unggul bermutu, Pupuk dan pestisida. Kemudian strategi peningkatan nilai tambah kopi yang dipaparkan adalah : Pembentukan unit pengolahan tingkat kelompok tani, Pemberdayaan petani melalui kelompok tani, Pembentukan kelembagaan koperasi pertanian.

\section{Proses Pengolahan Kopi}

Jenis proses olahan kopi ada tiga yaitu natural, honey dan full wash. Perbedaan terdapat pada urutan tahap proses setelah kopi di panen seperti yang diuraikan sebagai berikut : 1) Pengolahan secara natural process, memiliki tahapan pengolahan yaitu: Penjemuran buah cherry kopi, pelepasan kulit kopi, dan sortasi biji kopi. 2). Pengolahan secara honey process, memiliki tahapan pengolahan yaitu : Pelepasan kulit buah cherry kopi, Penjemuran buah kopi, Pelepasan kulit gabah, Sortasi biji kopi. 3). Pengolahan secara full wash process, memiliki tahapan yaitu : Pelepasan kulit buah 
kopi, Perendaman biji kopi, Pelepasan kulit gabah kopi, Sortasi biji kopi tahap setelah sortasi untuk semua jenis olahan yaitu proses roasting, proses grinding, dan pengemasan.

\section{Analisis nilai tambah kopi}

\section{Hasil penelitian RN. Tamaradewi, dkk, (2019) di KTH Cibulao Hijau menjelaskan bahwa :}

1. Kopi arabika natural process

- Input cherry kopi sebanyak $100 \mathrm{~kg}$ menghasilkan $14,3 \mathrm{~kg}$ green bean.

- Input $14,3 \mathrm{~kg}$ green bean menjadi $11,4 \mathrm{~kg}$ roasted bean.

- Input 11,4 kg roasted bean menghasilkan 11,4 kg kopi bubuk.

- Nilai tambah setiap produk green bean, roasted bean dan kopi bubuk adalah Rp 8.324, Rp 163.035 dan Rp 74.548.

- Rasio nilai tambah setiap produk secara berurutan adalah $43,12 \%, 53,82 \%$ dan $16,21 \%$.

- Tingkat keuntungan ( $\mathrm{rp} / \mathrm{kg}$ ) yang diperoleh untuk masing-masing olahan yaitu Rp 6.235, Rp 134.319 dan Rp 72.4432.

2. Kopi arabika honey process

- Input $100 \mathrm{~kg}$ cherry kopi $100 \mathrm{~kg}$ menghasilkan green bean $14,3 \mathrm{~kg}$.

- Input green bean $14,3 \mathrm{~kg}$ menghasilkan roasted bean $11,4 \mathrm{~kg}$.

- Input roasted bean 11,4 kg menghasilkan kopi bubuk 11,4 kg.

- Nilai tambah produk green bean, roasted bean dan kopi bubuk masing-masing adalah rp 5.709, rp174.483 dan rp 84.469.

- Rasio nilai tambah untuk setiap olahan secara berurutan adalah $34,7 \%, 59,15 \%$ dan $18,36 \%$.

- Tingkat keuntungan $(\mathrm{rp} / \mathrm{kg})$ yang diperoleh dari setiap masing-masing olahan yaitu Rp 3.619, Rp 145.767 dan Rp 82.364

3. Kopi arabika full wash process

- Input cherry kopi $100 \mathrm{~kg}$ menghasilkan green bean sebanyak 14,3 kg.

- Input green bean 14,3 kg menghasilkan 11,4 kg roasted bean. 
- Input roasted bean 11,4 kg menghasilkan 11,4 kg kopi bubuk.

- Nilai tambah produk green bean, roasted bean dan kop bubuk secara berurutan adalah Rp 3.735, Rp 182.091, Rp 84.548.

- Rasio nilai tambah setiap produk secara berurutan adalah $26,12 \%, 63,45 \%$ dan $18,79 \%$.

- Tingkat keuntungan ( $\mathrm{rp} / \mathrm{kg}$ ) dari masingmasing olahan yaitu Rp 1.644, Rp 153.375 dan $\operatorname{Rp} 82.443$.

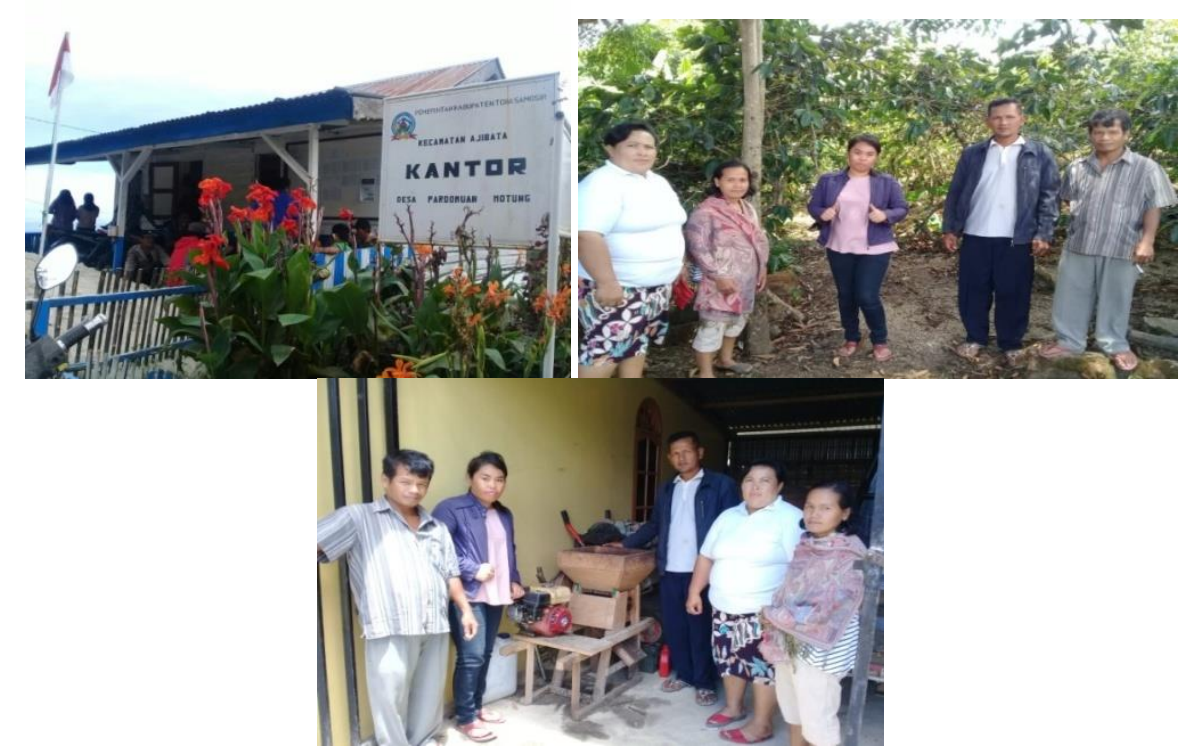

\section{Gambar 1. Lokasi Pengabdian/ kondisi lahan dan alat pengupas kopi yang dimiliki kelompok tani}

\section{KESIMPULAN}

Melalui pemaparan tentang strategi pengembangan dan peningkatan nilai tambah kopi maka diharapkan :

1. petani dapat menikmati hasil dan nilai tambah maksimal dari proses pengolahan dan penjualan kopi.

2. mampu meningkatkan kesadaran para petani tentang pentingnya proses pengolahan hasil panen mereka dan sekaligus juga memberikan pengetahuan kepada para petani bahwa pengelolaan kopi yang baik akan menghasilkan produk yang baik yang pada akhirnya akan memberikan harga yang baik pula.

3. petani mampu mengembangkan koperasi sebagai pelanjar pemasaran kopi. 


\section{DAFTAR PUSTAKA}

Admaizon, 2004. Agribisnis Kopi Arabika Kabupaten Solok dengan Pendekatan Kimbun. Solok: Warta Rimbun edisi 2/2004

Susila, Wayan R. dan Bambang Drajat, 2009. Agribisnis Perkebunan Memasuki Abad 21 beberapa Agenda Penting. http://www.ejournal.unud.ac.id.

Kustari, Reni. 2007. Perkembangan Pasar Kopi Dunia dan Implikasinya Bagi Indonesia. Pusat Analisis Sosial Ekonomi dan Kebijakan Pertanian. Bogor Sutriono, 2009)

RN. Tamaradewi et all, 2019. .Analisis Nilai Tambah Dan Strategi Pengembangan Usaha Kopi (Coffea, Sp) Di Kelompok Tani Hutan (Kth) Cibulao Hijau. Jurnal AgribiSains ISSN 2550-1151 Volume 5 Nomor 2, Oktober 2019 